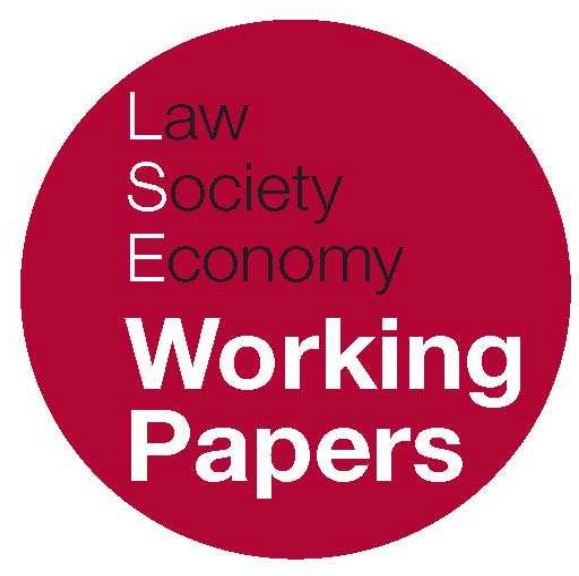

\title{
The Rise, Fall and Fate of Principles Based Regulation
}

\author{
Julia Black
}

LSE Law, Society and Economy Working Papers 17/2010 London School of Economics and Political Science

\author{
Law Department
}

This paper can be downloaded without charge from LSE Law, Society and Economy Working Papers at: www.lse.ac.uk/collections/law/wps/wps.htm and the Social Sciences Research Network electronic library at: http://ssrn.com/abstract=1712862.

(C) Julia Black. Users may download and/or print one copy to facilitate their private study or for non-commercial research. Users may not engage in further distribution of this material or use it for any profit-making activities or any other form of commercial gain. 


\title{
The Rise, Fall and Fate of Principles Based Regulation
}

\author{
Julia Black * $^{*}$
}

\begin{abstract}
The financial crisis has prompted a number of fundamental questions, not leaset of which is the relationship between financial institutions and regulators. In particular, the reputation of principles based regulation (PBR), lauded as a key example of 'new governance' techniques of regulation prior to the crisis, has taken a severe battering. Detailed rules did not fare much better, but advocates of 'new governance' techniques would not have expected them to: their failure was to be expected. It is the fate of PBR that should therefore cause us to look long and hard at what has become increasingly accepted wisdom amongst regulatory scholars and 'better regulation' practitioners over the last decade or so. This paper asks what lessons can be learned from the crisis as to the effectiveness and appropriate role of principles based regulation, and what future it may have. It sets out four 'ideal types' of PBR in the Weberian sense: analytical constructs that are rationalised abstractions of particular practices: formal, substantive, dyadic and polycentric PBR. It then charts the rise and fall of PBR in financial regulation over the last few years and offers some tentative predictions for its future.
\end{abstract}

\section{INTRODUCTION}

The financial crisis did not only bring into sharp relief the limitations of the structures of financial markets and the behaviour of its participants, it also called into question some critical aspects of international and national financial regulation. Many of the questions it prompted relate to highly technical matters, for example of prudential regulation and financial stability. Others, however, are more fundamental questions as to the appropriate nature of the relationship between markets and regulators, and the role that each should play in the regulatory

\footnotetext{
* Professor, Law Department, London School of Economics. This paper will be published in K. Alexander and N. Moloney (eds), Law Reform and Financial Markets (Cheltenham: Edward Elgar, forthcoming 2011). I am grateful to the editors for allowing me to publish the paper in advance of the edited book. The paper was first presented at the Hart Legal Workshop, Institute of Advanced Legal Studies, London in June 2009 and has been revised to take into account events up to October 2010. I am grateful to the participants for their comments and reactions to the paper, and to David Roach for comments on a previous draft. The usual responsibilities remain my own.
} 
regime. In particular, the reputations of four broad categories of regulatory approach and technique have suffered heavy casualties: principles based regulation, risk based regulation, reliance on internal management and controls, and market based regulation. It must be said that detailed, rules based regulation did not fare particularly well either, but as such a regulatory approach is largely unfashionable in the regulatory literature, few commentators would have expected it to do so. In contrast, each of the former set is a key example of 'new governance' techniques of regulation, ${ }^{1}$ which are far more strongly lauded by academics and 'smart' regulation policymakers alike. Their fate in the financial crisis should therefore cause us to look long and hard at what has become increasingly accepted wisdom amongst regulatory scholars and 'better regulation' practitioners over the last decade or so.

This article focuses on just one of those techniques: principles based regulation. It asks what lessons can be learned from the crisis as to the effectiveness and appropriate role of principles based regulation, and what future it may have. Principles based regulation (PBR) is a moniker that is loosely applied to a number of regulatory regimes, however, and has no clear definition. ${ }^{2}$ The article therefore first sets out four 'ideal types' of PBR in the Weberian sense: analytical constructs that are rationalised abstractions of particular practices. ${ }^{3}$ It then charts the rise and fall of PBR in financial regulation over the last few years and offers some tentative predictions for its future.

\section{WHAT IS PRINCIPLES BASED REGULATION?}

Rules, standards, principles come in different forms and much academic time and debate has been spent delineating the differences between them. Considerable efforts have been made, including by this author, to detail the advantages and disadvantages of each type of norm (detailed, vague, legal, non-legal, specifying processes or outcomes), to analyse when each should be used and how they can be used in combination, and to a lesser extent, to test their effects empirically. ${ }^{4}$ The question of when to use rules, principles, or standards has also become a policy

\footnotetext{
1 C. Ford, 'New Governance, Compliance and Principles-Based Securities Regulation' (2008) 45 American Business LJ 1; J. Black, 'Decentring Regulation: Understanding the Role of Regulation and Self Regulation in a "Post-Regulatory" World' (2002) 54 Current Legal Problem 103; J. Braithwaite, 'The New Regulatory State and the Transformation of Criminology' (2000) 40 British Jnl of Criminology 222; C. Scott, 'Regulation in the Age of Governance: The Rise of the Post Regulatory State' in J. Jordana and D. Levi-Faur (eds), The Politics of Regulation: Institutions and Regulatory Reforms for the Age of Governance (Cheltenham: Edward Elgar, 2004).

${ }^{2}$ L. Cunningham, 'A Prescription to Retire the Rhetoric of "Principles Based Systems" in Corporate Law, Securities Law and Accounting' (Boston College Law School Research Paper No. 127, 2007), at http://ssrn.com/abstract=970646.

${ }^{3}$ M. Weber, The Methodology of the Social Sciences (in E.A. Shils \& H.A. Finch (Trans and Eds), foreword by Shils, New York: Free Press, 1997), 88.

${ }^{4}$ See eg C.S. Diver, 'The Optimal Precision of Administrative Rules' (1983) 93 Yale LJ 65; C. Sunstein, 'Problems with Rules' (1995) 83 California LR 953; F. Schauer, 'The Tyranny of Choice and the Rulification of Standards' (2005) $14 \mathrm{Jnl}$ Contemp Legal Issues 803; R. Korobkin, 'Behavioral Analysis and Legal Form: Rules vs. Principles Revisited' (2000) 79 Oregon LR 23; F. Schauer, 'The Convergence of Rules and Standard' (2003) N.Z. LR 303; R. Baldwin, 'Why Rules Don't Work' (1990) 53 Modern Law Review 321; J. Black, Rules and Regulators (Oxford: OUP, 1997); J. Braithwaite, 'A Theory of Legal Certainty' (2002) 27 Australian Journal of Legal Pbilosopby 38; J. Black, M. Hopper, and C. Band, 'Making a Success of Principles Based Regulation' (2007) 1(3) Law and Financial Markets Review 191; Ford, n 1 above.
} 
issue in its own right. In some policy areas, though by no means all, they have been recognised as being particular 'technologies' of regulation and as having particular properties, properties which policymakers in some areas have consciously sought to use and exploit for a variety of ends. ${ }^{5}$

In financial regulation, the UK Financial Services Authority is notable for elevating PBR to a regulatory art form. But it is not alone. As Cunningham documents, in North America regulatory regimes for securities, corporations and accounting have been described as, and have positioned themselves as, being 'principled based'. 6 These monikers are more than just descriptions, however; they also carry significant normative content. Being 'rules-based' is usually denigrated as equating with nit-picking bureaucracy in which compliance with detailed provisions is more important than the attainment of an overall outcome. 'Principles-based', in contrast, evokes images of outcome orientated, flexible regulators harbouring ethical standards in largely responsible corporations.

At least, that is the picture that was conjured up pre-crisis. Pre-crisis, PBR was seen as the solution that firms and regulators were looking for to deliver an effective and responsive regulatory regime. Post-crisis, PBR is seen as being the source of the problem: light touch regulation that placed too much reliance on firms themselves to behave responsibly. Having been one of the regulators most committed to PBR, it is no surprise that the FSA responded with such force against the markets' betrayal. It had had so much reputational capital invested in PBR that when the crisis came, it had no option but to withdraw it from the market. In its place the FSA launched a new product under a different strap line (to use its own terms): 'outcome based regulation'. Meanwhile, other regulators are climbing on the PBR bandwagon just as it appears to be abandoned by one of its main proponents. In Japan, for example, the head of their Financial Services Authority asserts that it will seek to adopt the right balance between principles and rules in its drive for 'better regulation'.7 In the US, President Obama's blueprint for regulatory reform was committed to using principles based regulation in some form. ${ }^{8}$ The OECD continues to support the strengths of principles based regulation although ultimately cautions that the appropriate balance between rules and principles will depend on a number of country specific factors. ${ }^{9}$ The advocacy of PBR is not confined to financial regulation. In the UK, The Legal Services Board has stated that it will be a 'principles based regulator', for example. ${ }^{10}$ Both the Solicitors Regulation Authority and the Financial Reporting Council (FRC) have adopted a similar approach, but called it 'outcomes-focused'. ${ }^{11}$ The Walker review of

\footnotetext{
5 For discussion see Black, n 4 above and J. Black, “'Which Arrow?” Regulatory Policy and Rule Type' (1998) Public Law 77. ${ }^{6}$ Cunningham, $\mathrm{n} 2$ above.

7 T. Sato, 'Global Reform of Financial Regulation and its Implications' (Speech to the 4th Annual Japan Investment Forum, Tokyo, June, 2009).

8 Department of the Treasury, Financial Regulatory Reform: A New Foundation (2009), proposed that a new Consumer Financial Protection Agency should use a principle based approach to disclosure to consumers (64), and that the SEC and CFTC should seek a harmonised approach to their rules, in which the CFTC's principles should become more detailed (akin to those of IOSCO) and the SEC's rules should become more flexible (50).

9 OECD, 'Policy Framework for Effective and Efficient Financial Regulation: General Guidance and High-Level Checklist' (2009) 2 OECD Journal, Financial Market Trends, 21-22.

${ }^{10}$ Legal Services Board, Business Plan 2009/10 (London: Legal Services Board, 2009), para 30.

${ }^{11}$ Solicitors Regulation Authority, Achieving the Right Outcomes (London: Solicitors Regulation Authority, 2010).
} 
corporate governance enunciated more principles for institutional investors, further developed in the FRC's Stewardship Code, issued in July 2010.12

So what is PBR? I suggest that by adopting a two-dimensional analysis, four 'ideal types' of PBR can be constructed. The first dimension is the approach taken by the regulator: whether principles play a formal role in the practice of regulation or whether the regulators' approach has certain substantive characteristics. The second dimension is the institutional setting and relationship in which principles are mainly being deployed: This could be in the dyadic setting of regulator-regulatee, which is the normal focus of debates on PBR, where principles are used in attempts to change behaviour of individual regulatees. Principles can also be deployed in a decentred or polycentric regulatory regime as tools of orchestration or network management, amongst other things. For example, they are used in the global financial regulatory regime to set out core normative requirements which other regulators are meant to observe, elaborate, and implement.

Together, these form four variations or types of PBR: full and substantive; and dyadic and polycentric (see Diagram 1).13 Although portrayed diagrammatically as being in separate boxes, in practice the distinctions between the categories are not always clear-cut. And of course, a regulatory regime may have both full and substantive PBR together, operating in dyadic and polycentric settings.

\section{Diagram 1: Forms of PBR}

\section{Formal}

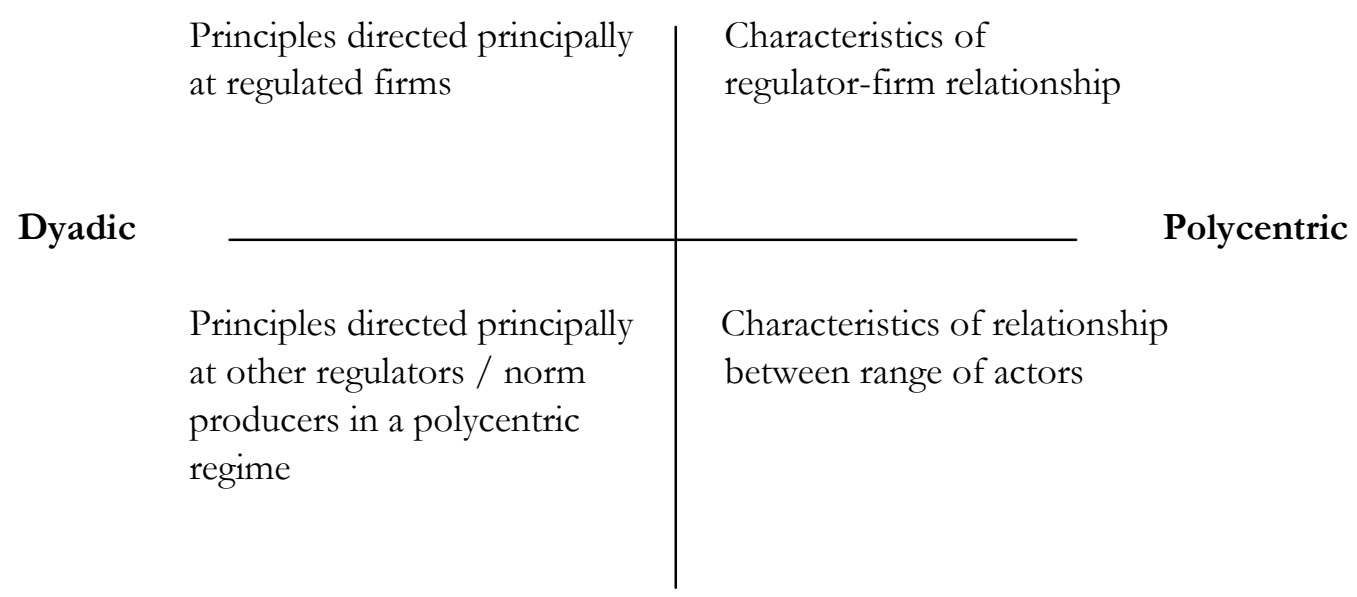

Substantive

\footnotetext{
12 Walker Review, A Review of Corporate Governance of UK Banks and other Financial Industry Entities (HM Treasury: London, 2009); FRC, Stewardship Code (London, July 2010).

${ }^{13}$ This is an elaboration of the argument made in J. Black (2008), 'Forms and Paradoxes of Principles Based Regulation' 3(4) Capital Markets LJ 425.
} 


\section{PBR AND REGULATORY STYLE: FORMAL AND SUBSTANTIVE PBR}

Regulatory styles can vary considerably across the various regulatory tasks of standard setting, monitoring and changing behaviour, or managing risks. Principles may play only a formal role: existing at the level of the rulebooks. Alternatively a regulatory style may in practice have some of the characteristics that are often ascribed to PBR regimes, what I term here 'substantive PBR'. The point about separating them is to distinguish what the rulebooks look like from how regulation actually operates in practice.

Formal PBR is PBR at the level of the rulebook. By this I do not mean that a regulator only regulates through using principles. Very few regulatory regimes rely wholly on principles. In practice they are usually accompanied by guidance, written explanations, and often more detailed rules. These rules may be written by regulators or firms (in dyadic PBR relationships) or by other actors (in polycentric PBR relationships), such as trade associations, other regulators, for example at national level in multi-level regulatory regimes, or other market actors, such as credit rating agencies, insurance companies, NGOs, or standard setters such as the ISO, as discussed further below. The number of rules written to 'fill out' the principles can be great: in the FSA's case, these rules ran to several thousand pages. But the chief characteristics of formal PBR is that principles have a dominant place in the organisation and interpretation of regulatory norms throughout the regulatory regime. Detailed rules or guidance flow from the principles, and the principles are used to interpret and apply those norms.

In substantive PBR, regulators adopt particular approaches to regulation. These approaches can be adopted irrespective of the form the rules take. In the debates on rules-based versus principle-based regimes, the focus is often on these substantive aspects, even if only implicitly, as each type of rule is asserted to be associated with particular forms of regulatory practice. However, it is important to note that regulatory practices can be quite divorced from the nature of the rules being implemented. The substantive character and nature of a regulatory regime cannot be discerned simply by analysing the types of norms it uses. Substantive PBR can operate in the absence of principles being present in the rulebooks; formal PBR need not be accompanied by any of the characteristics of substantive PBR.

There are a number of reasons why the substantive character of a regulatory regime may depart from its formal character. A key reason is that the regulator is not necessarily the author, or at least not the sole author, of the norms it has to implement. Regulators can be recipients of a rule-making process or co-authors within it, but they may not have autonomy to write their own rules. Rather, these rules can be formulated by legislatures that do not wish to confer on regulators the discretion to elaborate on principles, but wish to stipulate provisions in considerable detail, ${ }^{14}$ or by other rule-making bodies within the regulatory regime whose rules the regulator has to abide by or incorporate in its own rules. Thus even though it has extensive rule-making powers, the FSA is constrained in the extent to which it can adopt PBR in its rule books by EU legislation. ${ }^{15}$ Nevertheless, substantive PBR can be achieved through the flexible

\footnotetext{
${ }^{14}$ For discussion with respect to the British Columbia Securities Commission, see Ford, note 1 above.

15 A fact emphasised in paper accompanying the FSA's Turner Review. FSA, 'A Regulatory Response to the Global Banking Crisis' (Discussion Paper 09/2, London: FSA, 2009), para 11.8.
} 
implementation and enforcement of a highly detailed set of rules (and conversely, PBR in practice may end up as no better than detailed box ticking if the principles are given particularly 'hard edges' in the way they are interpreted by regulators or courts, or are coupled with a highly deterrence-based and unpredictable enforcement regime which prompts very conservative behaviour by firms).

Given the variety of regimes that are styled, or style themselves, as PBR regimes, the construction of an ideal type necessarily means that some regimes will accord more strongly with certain features than others. However, substantive PBR regimes may be said to have one or more of five key characteristics: These pertain to modes of interpretation, enforcement, compliance focus, distribution of responsibilities within the regulatory regime, and conscious reliance on internal management, or meta-regulation. To reiterate, each of these characteristics can be present independent of the presence of principles in the rulebooks.

First, substantive PBR regimes are characterised by a dense network of 'regulatory conversations': repeated and reasoned interchanges, conversations, between regulator, regulatee, and others as to the purpose and application of the principle. Others can play a key role in these conversations in practice, in particular consultants and advisors (but rarely consumers). In these conversations, it is not the case that any interpretation that the parties can agree upon will suffice; the interpretation is always structured by the goal the principle is trying to achieve or the value that it is expressing: to act fairly, or with integrity, or with due care and diligence, for example. Disputes over the application of principles are resolved not through detailed linguistic (legal) interpretive approaches but through purposive interpretations and consequentialist reasoning. The interpretive approach in resolving disputes ultimately depends on the approach adopted by the final arbiter of the rule's interpretation (court, regulator, ombudsman, or all three in different fora); the 'battle for interpretive control' can thus be critical. Further, responsibility for developing interpretations and applications is shared between regulator and regulatee, though each has somewhat different roles. Firms have to take responsibility for thinking through the application of the principle to specific circumstances; regulators have the responsibility to give clear guidance.

Second, substantive PBR regimes adopt particular approaches to enforcement. Under PBR, firms are required to think through the application of the provisions to particular situations to a far greater degree than they are with respect to a detailed rule. There is thus a greater exposure to 'interpretative risk' - the risk that they will make the wrong assessment. A 'wrong' assessment is here simply judged in pragmatic terms: it is one with which the ultimate arbiter of interpretation (regulator, tribunal, or court) does not agree. ${ }^{16}$ Those subject to the principles (or rules) will seek to minimise this risk by calling for greater clarification or even prescription from the regulator. In the absence of that clarification, the enforcement approach is critical. Regulators can manage firms' interpretive risk in two ways: by minimising its probability through issuing guidance or other aides to interpretation, or by minimising its impact through its enforcement approach. Minimising its impact means minimising the impact of the firms' interpretation not matching

\footnotetext{
16 Again, this is not to say that the normatively 'right' answer is simply one which the parties agree amongst themselves irrespective of the rule or principle; the point being made is a practical and operational one, not one which expresses a particular interpretive philosophy.
} 
that of the regulator or final arbiter of the rule / principle's interpretation, for example through due diligence defences. In a regime with a tough, punitive approach in which every minor infraction is met with a sanction, PBR will not survive. It will transform into a system of detailed requirements, as that is what firms will need. They will demand rules to provide them and the regulator, with clear boundaries. In order to maintain the central role of principles in a PBR regime, enforcement therefore has to be responsive to the firm's own attitude and behaviour.

A 'responsive' enforcement approach is not contingent on any particular rule design, however. ${ }^{17}$ It can operate in systems of highly detailed rules, or where the rules are mainly principles, or where there is a combination of the two. That said, different rule types make it easier for regulatory officials to deal with certain types of regulated firm, as Baldwin has pointed out. Those who know what they are meant to be doing and are generally inclined to do it (the well intentioned and well informed) are best dealt with using a negotiating strategy, which is easier to do using principles. In contrast, those who do not know what they are meant to be doing and even if they did would not be inclined to do it (the ill intentioned and ill informed) are best dealt with using a strategy that is more targeted, for which bright line rules are more effective. A supervisor can simply tell those firms: Just do this because that is what the rule says. ${ }^{\prime} 18$

The point here, however, is not what rule type is most effective for which type of regulated firm, though that is relevant, but the enforcement approach used. Substantive PBR requires a broadly 'responsive' mode of supervision and enforcement, in which negotiation as to the meaning, application and purpose of the rule plays a central role, and in which the focus is on the outcome that is to be achieved. ${ }^{19}$ However, whilst a 'responsive' approach to enforcement may be facilitated by rules of certain types, it is not contingent on them. So in the area of enforcement there can be, at least in this sense, substantive PBR without the form. The British Columbia Securities Commission provides a good example. As Ford explains, even though the $\mathrm{BCSC}$ has not been able to introduce principles, it has introduced the substantive aspect of PBR through changes to the manner in which it monitors and enforces its regulatory requirements. ${ }^{20}$

A third characteristic of substantive PBR is a focus on outcomes throughout the whole regulatory process. Again, there is no analytical correlation between using rules of a particular type (principles) and outcome based supervision, but having formal PBR facilitates outcomebased supervision. It depends how the outcomes are defined (and whether they really are outcomes rather than outputs). Targets, for example, can be extremely precisely defined, and as such open to gaming and 'creative compliance' as detailed rules. Studies of how hospitals and other public service providers 'game' the performance targets set for them by central government illustrate this very clearly. ${ }^{21}$ In the telling phrase, those subject to targets 'can hit the target and miss the point',22 just as firms can engage in 'creative compliance' or the gaming of

\footnotetext{
17 In Ayres and Braithwaite's original exposition there is no discussion of rule type; the issue is the nature of the dyadic interaction of regulator and regulatee: I. Ayres and J. Braithwaite, Responsive Regulation (Oxford: OUP, 1992).

18 R. Baldwin, Rules and Government (Oxford: OUP, 1995).

${ }^{19}$ What 'responsive' can consist of is elaborated in R. Baldwin and J. Black, 'Really Responsive Regulation' (2008) 71 Modern Law Review 59.

${ }^{20}$ Ford, $\mathrm{n} 1$ above.

21 C. Hood, 'Gaming in Targetworld: The Targets Approach to Managing British Public Services' (2006) 66(4) Public Administration Review 515.

22 ibid.
} 
detailed rules: complying with the letter but not the spirit of the rule. Outcomes which are defined in qualitative and / or behavioural terms: for example to act 'with integrity', 'fairly', 'in the best interests of the client', ${ }^{23}$ are far harder to game. It is possible to have outcome-based supervision without having formal PBR if the outcomes are identified and adopted as operational supervisory and enforcement norms in the course of regulatory practice. However, the absence of any formal principles articulating those outcomes or the values from which they are derived can hinder formal enforcement processes. For if a firm fails to achieve those outcomes but there is no breach of a detailed rule, ie gaming strategies are employed, then the regulator is largely impotent as there is nothing on which to base enforcement actions.

The fourth characteristic of substantive PBR is that the responsibility for ensuring that the objectives of the principles are met is shifted, in part, from the regulator to the regulated. More general rules (principles) allow firms greater discretion as to what to do. With that discretion come the need, and responsibility, for working out what they should do. Where the balance should be struck between firms thinking for themselves and the regulators providing guidance is endlessly contested; each thinks the other should be doing more. Firms want more specific guidance; regulators think firms should work it out for themselves. Firms do not want to do the regulators' job for them; regulators do not want to become unpaid consultants. This tension in their relationship, as to what the regulatory compact entails, is not unique to PBR regimes. Regulators implementing detailed rules face the same tension, as the NAO's recent review of the five largest regulators in the UK illustrates. ${ }^{24}$ But PBR involves a significant shift in responsibility to firms, and requires a substantially different set of skills on the part of inspectors and compliance staff to engage in the negotiations and qualitative judgments that are entailed.

The final characteristic of substantive PBR is a conscious and deliberate focus by the regulator on the firm's internal systems of management and controls - referred to in the regulatory literature as 'meta-regulation' or management based regulation. 25 As with enforcement, meta-regulation can and does operate in systems where there are detailed rules. Given that any regulatory regime requires firms to internalise the regulatory requirements into their own systems and processes for it to be complied with, meta-regulation could be argued to be not so much a radical new strategy as regulators making a virtue out of a necessity, or at least recognising that necessity. Regulators always have to rely on firms' internal management regimes even for one-man firms simply because regulators cannot be continually present in all the firms they are responsible for all the time. However, in management-based or meta-regulatory regimes, reliance on internal management is 'designed in' to the regulatory regime, and the regulator consciously and deliberately focuses its attention on ensuring that the firms' own internal rules, systems, and processes are such that they will ensure compliance. As Power comments, internal management systems become the critical interface between regulatory and

${ }^{23}$ Outcomes are usually distinguished from outputs in performance evaluations: outputs are easier to game than outcomes.

${ }^{24}$ National Audit Office, Regulatory Quality: How Regulators are Implementing the Hampton Vision (London: National Audit Office, 2008), para 4.5, notes that 'Regulators with direct inspection responsibilities face [the] challenge of determining where to draw the line between their preferred stance of neutral guidance provider and educator of business and the more hands on consultant-cum-management role many businesses seem to want'.

${ }^{25}$ C. Parker, The Open Corporation (Cambridge: CUP, 2000), ch 9. 
business values, and hence between society's and the organisation's goals and operations. ${ }^{26}$ Again the emphasis is on substance not form, under the substantive model. Regulators and firms should be focused on the outcomes those systems and processes deliver, not just on the form they take.

\section{PBR AND REGULATORY SETTINGS: DYADIC AND POLYCENTRIC / NETWORKED PBR}

Regulators stand in different institutional positions and relationships vis a vis other actors in a regulatory regime. Usually when we talk of regulatory regimes we think in terms of a dyadic relationship of regulator-regulatee. The regulator can be state or non-state, as can the regulatee, and they can exist in any combination (state regulating non-state; non-state regulating state; state regulating state; non-state regulating non-state). In dyadic PBR, the focus of analysis (and use of the principles) is to affect the behaviour of the regulatee. This is the normal focus of analysis and debates on PBR, and as explained above, PBR can exist simply at the level of the rule books, and / or can be manifested in particular regulatory approaches.

But regulatory regimes are often comprised of dense, polycentric networks of actors. All or some of these actors can be regulators themselves, depending on which aspect of the overall regime we are focusing. In polycentric PBR, principles are used in the management of networks of regulators. PBR in this context can also be substantive or formal. Principles can be used explicitly or implicitly to manage a network of regulators by distributing formal powers, responsibility, and discretion within the regulatory regime. Principles implicitly or explicitly confer discretion on other regulators, as well as firms, to develop more detailed interpretations and applications. The extent to which they do so depends significantly on the space that they allow through their phrasing. One of the critical aspects of rules or principles is that they can both structure and distribute discretion, conferring space not just between rules / principles but also within them in which actors can exercise choice. ${ }^{27}$ To give an obvious example, a norm which requires me to drive at a maximum of 30 miles per hour gives me less discretion to determine at which speed to go than one that requires me to drive at a reasonable speed. One of the contested issues within EU financial regulation, for example, is whether EU directives leave enough, or too much, room for national regulators to adapt the provisions to local markets or political preferences, and whether its provisions impose minimum or maximum harmonisation.

These more detailed interpretations could be developed by other interpretive intermediaries', for example non-state regulatory organisations, trade associations, and others who produce guidance on the meaning and application of the principles. In the UK, this is a strategy which the FSA had been using to an increasing degree. In the area of money laundering, it reduced its rules to two pages, preferring to rely instead on the provisions of the Joint Money Laundering Steering Group (JMLSG). Reducing the amount of rules in the area of money laundering was worthwhile, but the equivalent of picking low-hanging fruit - the rules as they

\footnotetext{
${ }^{26}$ M. Power, Organized Uncertainty: Designing a World of Risk Management (Oxford: OUP, 2007), 42.
}

27 Black, $n 4$ above, ch 1. 
were mainly reiterated the provisions of either the statutory instruments or the JMSLG's guidance. There are other examples where the FSA actively facilitated the production of guidance by requiring representatives from different parts of the industry to agree on the contested issue of soft commissions. As part of its PBR initiative, the FSA also introduced a system of 'confirmed' guidance, whereby it will 'confirm' industry guidance on the application of the principles. The status of such guidance, the FSA stated, was that it will act as a 'shield' not a 'sword'. In other words, conduct in accordance with the guidance could be used as a 'shield' against enforcement action (though it did not have the formal status of a safe harbour), but nonconformity with the guidance would not be used as a 'sword' by the FSA with which to impale firms. ${ }^{28}$

Polycentric or network PBR is also manifested at the international level. Transnational financial regulation is characterised by such a dense network of regulatory actors, both state and non-state, operating at the global, regional, and national level, and by a network of principles. Formal PBR is manifested in the plethora of principles issued by the various international committees. The transnational network of principles is denser in some areas than others. Some sets of principles interact through their inter-textuality, interconnecting through the incorporation of definitions or provisions from each other, or incorporation of entire codes themselves, or through cross-referencing, producing particularly dense networks of norms. Others do not interact at the formal level (ie in their texts) but are brought together through mechanisms of implementation and enforcement, including systems of peer review. A notable example is the Financial Sector Assessment Programme, the review (inter alia) of the compliance of financial regulators and their national governments with a compendium of codes and principles issued by the main international standard-setting bodies. Under this programme, regulators and governments are assessed by a peer group of regulators as to the degree to which they have implemented the codes. In the wake of the financial crisis, the newly reformulated Financial Stability Board announced it will enhance and reinforce this process. ${ }^{29}$ Other principles or codes are less integrated into the network, and simply exist side by side with other sets of principles with no explicit cross-referencing or common enforcement mechanism, but represent attempts by their authors to establish a place in the international dialogue and to position themselves in the institutional domain..$^{30}$

Although the degree of density and interaction may vary, as do the individual reasons for their production, many uses of principles at the international level share a common aim: it is through the network of principles, and increasingly through their enforcement, that regulators seek to regulate other regulators. In networked or polycentric PBR principles are used in an attempt both to confer and to structure the discretion of regulators and set the terms of their inter-regulator relationships, as they are in the more familiar regulator-firm relationships. As in that more familiar relationship, networked or polycentric PBR can have formal and substantive elements. Formally, polycentric PBR can exist at the level of rules. Substantively, it can be manifested in the operation of the management of the regulatory network. However, there can

${ }^{28}$ FSA, Principles Based Regulation: Focusing on the Outcomes that Matter (London: FSA, 2007).

${ }^{29}$ FSB, Framework to Strengthen Adherence to International Standards (2010).

${ }^{30} \mathrm{eg}$ OECD, Principles for Efficient and Effective Financial Regulation (Paris: OECD, 2009). 
be a gap between formal enunciation of principles and their implementation in any regulatory regime. In financial regulation this is particularly manifested at the international level. The international financial regulatory regime exhibits strong formal PBR in so far as there is any number of principles of regulation. As to the substance, of course one of the criticisms of international financial regulation is that there is surfeit of norms but at least until now no systematic means for ensuring their implementation; there was only weak substantive regulation of any form.

\section{CHARTING THE RISE (AND FALL?) OF PBR}

\section{THE RISE}

In the period before the financial crisis, the attractiveness of PBR was significantly on the rise both in terms of regulatory practice and in political rhetoric. PBR has some obvious attractions, and as noted above, resonated well with the new governance strategies being propounded by academics and some policymakers alike. In providing the framework in which firms can organise their own processes to achieve the substantive outcomes the regulator seeks, PBR both relies on and reinforces the image of the self-observing, responsible organisation which is a central feature of governance strategies. ${ }^{31}$ Regulatory conversations take centre stage as the meaning and application of principles are elaborated in iterated communications between regulator and regulatee. ${ }^{32}$ Rigid divisions of responsibility for producing rules between public and private actors are eschewed as third parties to the regulator-regulatee relationship such as trade associations are brought in to develop interpretations and guidance on their meaning. The strategy links with another key 'new governance' strategy, that of 'meta-regulation' or management based regulation, in which regulators focus not on detailed compliance but on whether the firm's internal systems and processes can deliver the outcomes which the regulator seeks. ${ }^{33}$ Principles impose outcomes to be achieved, not detailed processes for achieving them, thus allowing room for local or 'bottom up' elaboration and customisation. They can thus help to overcome the problems of scale which all regulatory systems face: the move from the aggregate and the general, which is the level at which rules and principles operate, ${ }^{34}$ to the local and the particular, which is the site of their application. ${ }^{35}$

The FSA had styled itself as an evidencebased, risk-based, and principles-based regulator, but it was the last of these self-descriptions which caught political attention. The FSA itself put forward cogent reasons for adopting PBR which accord with the advantages of principles often noted in academic commentaries, and indeed echoed in the OECD's recent Principles. ${ }^{36}$ It

\footnotetext{
31 On those strategies, see Parker, n 25 above, ch 9; Power, n 26 above, 41-42.

32 See further J. Black, 'Talking about Regulation' (1998) Public Law 77.

33 Parker, n 25 above; C. Coglianese and D. Lazer, 'Management Based Regulation: Prescribing Private Management to Achieve Public Goals' (2003) 37(4) Law and Society Review 691.

34 As do policymakers.

35 Black, n 4 above.

36 OECD, n 30 above.
} 
offered four main reasons for adopting a more principles based approach. Firstly, effectiveness: detailed rules, it argues, have been incapable of preventing misconduct in a range of areas, such as mis-selling of retail financial products. Secondly, durability: regulation that focuses on outcomes is more able to adapt to a rapidly changing market environment than one that is based on prescriptive rules. Thirdly, accessibility: principles are far more accessible to senior management and smaller firms in particular than a bewildering mass of detailed requirements. Fourthly, fostering substantive compliance: a large volume of detailed provisions can divert attention towards adhering to the letter rather than the spirit of the rules, making it less likely that the FSA will achieve its regulatory objectives. ${ }^{37}$

However, there was more to the PBR debate pre-crisis than regulatory functionality. In the US-UK context, and to an extent in the EU-UK contest, PBR became intimately embroiled in a competition between regulators (and their governments) for business. There is no doubt that, at least at the rhetorical level, PBR was a weapon in the fierce battle for business between London and New York. ${ }^{38}$ The political attraction of principles-based regulation lay in its rhetorical invocation of a Utopian world. In this regulatory Utopia, regulation is targeted and focused, and preferably harmonised across jurisdictions, regulated firms are given the flexibility they need to get on with running their businesses, and consequently regulatory outcomes are achieved with no undue cost to business. It is a world in which regulators have sufficient perspective on and understanding of the problems and issues that they confront to be selective and to identify the key issues on which regulation should focus and sufficient agreement on principles and purposes to be able to agree upon a common framework, and in which regulated firms are given the flexibility and responsibility to develop their own systems for ensuring that the regulatory principles are adhered to, but in a way which means their businesses can operate efficiently and innovatively in a stable regulatory environment.

The rhetoric of principles regulation thus invoked, not deregulation, but a re-framing of the regulatory relationship from one of directing and controlling to one based on responsibility, mutuality, and trust. Regulators and regulatees move from a directing relationship of telling and doing, to a relationship of responsibility, mutuality, and trust in which regulators communicate their goals and expectations clearly in principles and apply those principles predictably, regulatees adopt a self-reflective approach to the development of processes and practices to ensure that these goals are substantively met, and, critically, both trust each other to fulfill their side of this new regulatory bargain.

This is a powerful vision with obvious political appeal for politicians, regulators, and firms alike. In less Utopian visions, of course, PBR is either simply a license for backsliding - for allowing regulatees to do what they want with regulators' pandering not kept in check by detailed rules which they have to enforce, or conversely, PBR is simply a license for regulators to put the boot in retrospectively when they decide that a firm's conduct is not up to scratch, with regulators' arbitrariness not kept in check by detailed rules to which they can be held accountable.

\footnotetext{
${ }^{37} \mathrm{FSA}, \mathrm{n} 28$ above, 6.

38 The rhetorical battle has led Cunningham to argue that the debate should be abandoned and refocused on fundamentals: Cunningham, n 2 above.
} 


\section{THE FALL}

The higher the climb, the bigger the fall, and the reputation of PBR suffered a significant setback in the wake of the crisis. The FSA was forced into a 'product recall', and re-launched itself under the new strap line of an 'outcomes based regulator'. In the Discussion Paper that accompanied the Turner Report, it described the change thus:

The FSA has always considered itself to be principles-based in carrying out its supervisory work, preferring, where appropriate, a high-level articulation of what is expected of regulated firms over prescriptive rules. This enables firms to decide how to align their business objectives with the specified regulatory outcomes. The focus is not on the principles themselves but on judging the results of the actions of the firms and the individuals that the FSA supervises. In this way, a better articulation of the FSA's philosophy is that it is an outcomes-focused regulator, firmly committed to a risk-based and proportionate approach. ${ }^{39}$

As Hector Sants, the FSA's chief executive, explained:

The whole point of outcomes [...], is that we want the supervisors to supervise, ie, to give consideration to whether the actions which companies are taking are leading to consequences which work in the best interests of society, consumer and the markets. We want them to think ahead, anticipate, think what is going to happen next, think whether what is going to happen next is going to work for society. That is what we mean by outcomes-based regulation. It is always difficult to capture that in one word but the point is clear. They need to be forward thinking, braver, intrusive and get involved. ${ }^{40}$

So what has changed in the FSA's approach? What has not changed is the rulebook, or at least not in ways that change its character. The 11 Principles for Business are still in place. Although its ability to use principles throughout its rule book is heavily circumscribed by the need to implement European legislation, the FSA relies extensively on a variety of other codes and principles embedded within the Handbook wherever it can. Notable amongst these are the Statement of Principles for Approved Persons, which the FSA is proposing to enhance in a number of respects, ${ }^{41}$ and its recently introduced Remuneration Code, discussed further below. ${ }^{42}$

PBR has been retained in the sense that the FSA still seeks, where it can, to move away from prescriptive rules to a higher level articulation of what the FSA expects firms to do. As Sants explained again, 'In other words, it [principles based regulation] helps emphasise that what really matters is not that any particular box has been ticked but rather that when making

\footnotetext{
${ }^{39} \mathrm{FSA}, \mathrm{n} 15$ above, para 1.64.

40 Treasury Select Committee, 'Minutes of Evidence 25th February 2009, Response to Q2235'.

${ }^{41}$ FSA, Effective Corporate Governance (Significant Influence Controlled Functions and the Walker Review) (Consultation Paper 10/3, London: FSA, 2010).

42 FSA Handbook, SYSC 19; for discussion see FSA, Reforming Remuneration Practices in Financial Services (Policy Statement 09/15, FSA: London, 2009).
} 
decisions, executives know they will be judged on the consequences - the results of those actions. ${ }^{43}$

However, the FSA no longer looked to Principles to be the means to achieve its outcomes, and withdrew from the strategy of 'light touch' regulation. Post-crisis, there was a fundamental change in the FSA's supervisory approach, at least (and this is an important qualification) with respect to its supervision of high impact financial institutions, notably the large banks. The change has been both philosophical, at least in a 'lite' sense, and operational.

At the more ideational level, as Lord Turner, incoming chair of FSA, explained, the previous regulatory philosophy had been forged in the meeting of two distinct philosophies: one economic, the other political. The dominant economic philosophy, held not just by selfinterested market participants but also by independent academic economists in the UK and elsewhere, was that markets were self-correcting and that firms were best placed to manage their own risk.

This economic philosophy was coupled, at least in the UK, with a political attitude which was regulation should be 'light touch'. This, Lord Turner argued, had a significant role to play in shaping FSA's approach, not withstanding its formal independence. In his evidence, Lord Turner explained, 'I think it is also the case that that [economic philosophy] existed within a political philosophy where all the pressure on the FSA was not to say: "Are you looking more closely at these business models?" but to say: "Why are you being so heavy and intrusive? Can you not make your regulation a bit more light touch?"'44

The resulting combination produced a regulatory system based on the twin assumptions of self-correcting markets and responsible management cased in a political context in which the worst offence the regulator could commit was to cause London to lose business. The FSA's regulatory philosophy was therefore to focus on organisational structures, processes, and systems and whether the reporting lines were correct. Its view was that it was not the function of the regulator to cast questions over the overall business strategy of the institution. In his evidence to the Treasury Select Committee, Lord Turner explained:

I think there was a philosophy of regulation which emerged, not just in this country but in other countries, which was based upon too extreme a form of confidence in markets and confidence in the ideas that markets were self-correcting, which therefore believed that the fundamental role of the supervision of financial institutions, in particular banks, was to make sure that processes and procedures and systems were in place, while leaving it to the judgment of individual management to make fundamentally sensible decisions. As Alan Greenspan said, that is the intellectual framework which has received an extraordinary challenge. ${ }^{45}$

\footnotetext{
${ }^{43}$ H. Sants, 'Delivering Intensive Supervision and Credible Deterrence' (Speech delivered to the Reuters Newsmakers Event, 12 March 2009).

${ }^{44}$ Treasury Select Committee, 'Minutes of Evidence 25th February 2009, Lord Turner Response to Q2145'. See also his response to Q2160: 'it [the political philosophy] was expressed in speeches on both sides of the House but which suggested that the key priority in regulation was to keep it light rather than to ask ever more searching questions'.

${ }^{45}$ Treasury Select Committee, 'Minutes of Evidence 25th February 2009, Lord Turner Response to Q2156'.
} 
The FSA still focuses on internal management and controls, but in a more substantive and less formalistic way than before. To quote Turner again, its approach shifted from focusing on structured systems and procedures 'to one which is focused on understanding the fundamental economics of the banks we are dealing with'. ${ }^{46}$ The mantra changed to 'intensive supervision', and in which the FSA 'make[s] judgments of the judgments of firms' senior management and require action if, in their view, the latter pose risks to the FSA's objectives'. ${ }^{47}$

There are four strands, in effect, to the FSA's model of 'intensive supervision'. The first is a much closer attention to the implementation of its risk-based system of supervision and a greater focus on risk identification and the integration of macro-prudential analysis into firm-specific supervision. The lesson of Northern Rock was that the FSA was operating as an organisation in which there was considerable bifurcation between the supervision that Northern Rock was meant to receive and that which it received in practice. It was meant to be monitored on a 'close and continuous' basis, though ranked as relatively low impact in the risk based system in place at the time. The 'close and continuous' monitoring was meant, amongst other things, to provide a window on the bank through which supervisors could see whether there were any risks emerging. In practice, far from being 'close and continuous' the monitoring was remote and ad hoc. As a result, the regulator as a whole had one view of the bank in which it assumed that far more monitoring was occurring than actually was. ${ }^{48}$

Northern Rock was a massive shock to the FSA, and it fundamentally reshaped the implementation of its risk-based approach to high impact firms as a consequence. The Risk Division was moved from the periphery to the centre of the organisation. It has also become the organisation's own compliance division. Key internal supervisory meetings are organised by the Risk Division, and are not quorate unless a member of the Risk Division is present. The Risk Division signs off on all supervisory plans, and also assesses the participation of each member present for the purposes of their own internal review and promotion. Supervisory planning meetings for high impact firms are attended by those from all divisions responsible for monitoring it, as well as by economic specialists. Macro prudential issues are integrated into each supervisory plan, and into the firms' day-to-day supervision. It has developed a highly complex system of internal governance, involving significant numbers of senior people from across the organisation in the supervision of high impact institutions with a considerable impact on resource allocation within the organisation, and supervisory staff have increased by 30 per cent. ${ }^{49}$

The second is a shift in the manner in which FSA relies on senior management. That reliance is now much more sceptical and far less trusting than it was before. In Hector Sants' memorable phrase, ' $[\mathrm{A}]$ principles-based approach does not work with individuals who have no principles. ${ }^{50}$ Pre-crisis, there was a far more accepting culture within FSA that they could trust the picture that the large firms painted of themselves. Now, there is a far more intensive and sceptical supervisory process that looks at how those systems operate in practice, a change which

\footnotetext{
46 Response to Q2148.

${ }^{47} \mathrm{FSA}, \mathrm{n} 15$ above, para 1.66

${ }^{48}$ FSA, Internal Audit Report, The Supervision of Northern Rock: A Lessons Learned Review (London: FSA, 2008).

49 There has also been a shift in resource allocation from a roughly 60:40 split between conduct of business and prudential divisions to a direct reversal of those proportions. Communications between FSA officials and author; notes on file with author.

50 Sants, n 43 above.
} 
is linked to the increased focus on outcomes, discussed below. Underlying this is a significant reduction in the trust that the FSA is prepared to place in firms' senior management to do the job they are appointed (and extremely well paid) to do, and indeed to appoint people to positions that they are competent to hold.

One example of this shift is its increased role in approving internal appointments to those occupying 'significant influence functions' under the Approved Persons Regime, and the extension of the positions to which the code applies. ${ }^{51}$ The FSA has always imposed corporate governance provisions on regulated firms that are significantly above those imposed through the Combined Code and company law. Since its inception it has required those occupying certain strategic and operational functions within authorised firms to have separate regulatory approval under a 'fit and proper' test, and has subjected them to individual responsibilities set out in the Approved Persons regime. However, the process of approval had been largely administrative and had focused primarily on the 'properness' of the person, investigating whether they had criminal convictions no matter how minor or irrelevant (eg driving offences). Indeed the FSA had within the last couple of years revised the regime to reduce the number of times that approval needed to be sought for more client-facing functions to reduce the administrative burdens on firms. This reduction had been much lauded in its 'better regulation' approach outlined in 2007.

Post-crisis, the FSA started taking the approval role far more seriously for those who are applying to occupy 'significant influence functions' within authorised firms, focusing on their 'fitness' and competence, not just their 'properness'. It has started interviewing those to take significant influence functions (SIFs), and between October 2008 and January 2010 had conducted 332 interviews, rejecting 25 applicants, ${ }^{52}$ and if anecdotal evidence is to be believed, refusing to shortlist even more. This focus on competence in appointment is matched by a policy to take enforcement actions against individuals not just for breach of probity but of competence. ${ }^{53}$ As with other regulators, it also started scrutinising remuneration structures within financial institutions. ${ }^{54}$

There is also a notable extension here in the focus on who takes the responsibility for managing the firm. Pre-crisis, the focus was on senior management. Post-crisis there is a shift, at least in the UK, to placing greater responsibility on non-executive directors and on shareholders, as evidenced by the FRC's Stewardship Code, noted above. ${ }^{55}$ As the FSA is careful to point out, there are limits to what regulation can achieve: 'regulators make no claim to be infallible.' Moreover, regulation should not be about restricting firms' risk taking per se. However the emphasis is now not only on firms' senior management, but also on their non-executive

\footnotetext{
${ }^{51}$ FSA, Dear CEO Letter, Approving and Supervising Significant Influence Functions: Our New Intrusive Approach (12 October 2009); FSA, n 41 above.

${ }^{52}$ FSA/PN/015/2010 (28 January 2010).

53 See M. Cole, 'Speech to Enforcement Law Conference' (18 June 2008). It imposed its first fine against a chief executive

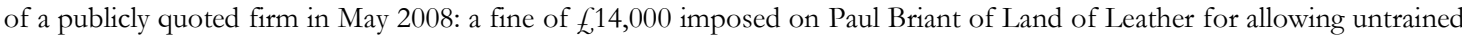
sales staff to sell payment protection insurance (PPI). The firm was fined $f_{2} 210,000$.

${ }^{54}$ FSA, Code on Remuneration (2009).

55 See for example P. Myners, Financial Services Secretary to the Treasury, 'Speech to the NAPF Corporate Governance Seminar' (Cheapside, London, HM Treasury PN 14/10, 9 February 2010); Walker Review, n 12 above; FRC, Stewardship Code (London, 2010).
} 
directors, shareholders, and auditors, who together 'carry primary responsibility for their actions and resulting consequences'. ${ }^{56}$

The third dimension to the FSA's changed approach is its focus on outcomes. The FSA states that it is now far more concerned with testing whether firms have delivered the right regulatory outcomes, and to an extent, with anticipating whether they will deliver those outcomes in the near future. It is a 'move from regulation based on facts to regulation based on judgements about the future'. ${ }^{57}$ Here again, caution is merited. The FSA's 'treating customers fairly' (TCF) initiative was all about focusing on outcomes, which had led to both firms and the FSA having to grapple with what 'fairness' meant in the context of the firm-customer relationship. The difference between the two perspectives was well illustrated in the debate between 'suitability' and 'satisfaction'. Firms argued that they could use customer surveys of 'satisfaction' as evidence that they delivered suitability; the FSA in contrast argued that as the products are opaque and customers cannot assess suitability for themselves, they might be satisfied even if sold an unsuitable product. ${ }^{58}$

So the move to 'outcomes' is not without precedence; rather again it provides an illustration of the twin-track approach that the FSA adopted pre-crisis between retail and wholesale regulation. The increased focus on outcomes across the board is linked, as noted above, to the manner in which the FSA assesses firms' ability to manage the risks they are taking. The crisis revealed significant flaws in the risk management systems of all large financial institutions, not just those in the UK. At fault were not only inadequate risk models or organisational structures and reporting lines, but also entire organisational cultures. 'Risk' and 'compliance' were the Cinderella enclaves of large financial institutions, relatively underpaid and significantly overlooked both in the day-to-day operations of the firms and in their strategic management. ${ }^{59}$ Just as FSA found that having pristine processes on paper does not guarantee their implementation within its own organisation, it has recognised the same is true for those it regulates. So there is reliance on senior management, but now that reliance is more sceptically held and is focused on the delivery of outcomes, not the presentation of structures and processes.

Finally, it has adopted a policy of what it terms 'credible deterrence'. The FSA has long been criticised for failing to take any successful enforcement actions against insider dealing and market abuse. These are notoriously difficult-to-prove offences, and so lack of successful actions does not necessarily point to inadequate investigations or lax enforcement processes. However, even with respect to less complex breaches of the regulatory rules, its fines have not always been particularly high, with a few notable exceptions, and have certainly been lower than in the US. Again internal organisational changes have been focused on producing a more integrated organisation in which the enforcement division is beginning to be brought in earlier in the overall monitoring and supervisory processes, and not regarded as an 'end of pipe' division. Fines levels have been increasing, rising 53 per cent in 2009-2010. Further, as noted above, a critical policy decision has been taken to take enforcement action against senior individuals, not

\footnotetext{
${ }^{56}$ FSA, n 15 above, para 11.10.

57 ibid.

${ }^{58}$ FSA, Treating Customers Fairly: Progress Update (London: FSA, 2008), 13.

${ }^{59}$ See eg UBS, Shareholders Report on UBS's Writedowns (2008); G. Kirkpatrick, 'The Corporate Governance Lessons from the Financial Crisis' (2009) 1 Financial Market Trends OECD.
} 
just the companies they run. In March 2010, the FSA announced that it would adopt a policy of raising fine levels. Under the new framework, fines will be linked more closely to income and be based on up to 20 per cent of a firm's revenue from the product or business area linked to the breach over the relevant period; up to 40 per cent of an individual's salary and benefits (including bonuses) from their job relating to the breach in non-market abuse cases; and a minimum starting point of $£, 100,000$ for individuals in serious market abuse cases. ${ }^{60}$

A number of things have not changed, but this does not indicate that the FSA is still 'light touch'. Rather, it is that there were pockets of highly intensive supervision going on within the FSA, but that the political context at the time meant that these could not be trumpeted as examples of principles based regulation as loudly as the 'light touch' message could. A lot of the PBR rhetoric has been just that, rhetoric. In fact, when the FSA decided in 2007 to launch the PBR strap line and construct its identity as a 'principles based regulator', it used as a basis for demonstrating that this was not such a major change in approach an initiative which it had launched in the retail sector the previous year: the Treating Customers Fairly initiative, or TCF. TCF was based on Principle 6 of the Principles for Business, which requires firms to 'treat customers fairly'. Under a deliberate quirk of drafting, 'customers' means only retail customers, and so this was firmly a retail markets, conduct-of-business initiative. As such it was far removed from the wholesale financial institutions, and thus from the battle for that wholesale market business between international financial centres in which the 'light touch' mantra, deployed by politicians, played such a role.

TCF was in practice very far from light touch. ${ }^{61}$ It had a set of six outcomes which firms were required to deliver, developed quite separately from the individual rules to which they were also subject (though with some overlap, eg in relation to suitability). Firms were required to produce management information demonstrating that they were meeting these outcomes. They also had to put in place novel ways of collecting that information, in particular through having mandatory 'mystery shopping' checks on their sales teams. Moreover, the FSA required firms to demonstrate that they were treating customers fairly at all points in the product chain, not just in the sales process. Rather every stage from product development, through marketing, through commission and remuneration structures, through to the sales and post-sales process firms were required to demonstrate that they achieved the TCF outcomes. This has far more in common with the newly heralded 'intensive supervision'. Why could the FSA 'get away' with such an intrusive approach here and not with respect to the wholesale activities of the big banks? A very different political context is one reason: there has been a long history of mis-selling in the retail markets, and consumers are constituents. Further, the retail and wholesale markets have different geo-economic profiles: there is no intense international battle for retail business, but there is for the high octane, high numbers wholesale business. Retail markets are also far less integrated than

${ }^{60}$ FSA, Enforcement Financial Penalties (Policy Statement 10/4, London: FSA, 2010).

${ }^{61}$ Contrast the coalition government's consultation paper, which criticised the FSA for not focusing sufficiently on retail regulation: HM Treasury, A New Approach to Financial Regulation: Judgement, Focus and Stability (Cm 7874, HMSO, London, 2010). 
the wholesale markets, even in the EU, ${ }^{62}$ and not nearly as peripatetic, and so less able to respond to more intensive supervision by moving jurisdiction.

Prior to the crisis, therefore, the FSA was thus already performing intensive, outcomesfocused supervision based almost entirely on one Principle. Moreover, it had also been changing its enforcement approach to taking enforcement actions based on breach of Principles alone. This was a significant change from when it was first formed, when its initial Chair and Chief Executive reassured firms that the FSA would not take enforcement action on the breach of a principle alone. In fact, the levels of enforcement actions based solely on principles had risen from 30 per cent in $2006 / 2007$ to 44 per cent in $2007 / 2008 .{ }^{63}$ Fine levels had also been increasing prior to 2009.

Neither of these examples is put forward to deny that the FSA has had a fundamental change of approach. Rather they are put forward as warnings not to take the rhetoric of regulators, and in particular the rhetoric of politicians about regulators, too seriously. Both of these initiatives were not only taking place whilst the FSA was styling itself as a 'principles based regulator'. They were used by the FSA as examples of what it did as a 'principles based regulator'. What is the case, however, is that neither approach, and particularly not the TCF model of supervision, spilled over into prudential supervision. If TCF and the changing patterns of enforcement were illustrations of what the FSA meant by being 'principles based', one of the problems was arguably not that the FSA was 'too' principles based, but that it was not principles based enough.

\section{THE FATE OF PBR}

\section{FORMAL PBR}

The fate of formal PBR looks better than the fate of one of its key proponents, the FSA. The fate of the FSA is, at the time of writing, not looking particularly rosy. The coalition government is currently consulting on proposals to move prudential supervision to the Bank of England and create an agency for retail and markets regulation. Whatever emerges, it is by no means clear that the label 'principles based regulator' will be deployed in the near future, though this may change. The government's consultation paper is actively seeking ways in which to ensure the new prudential regulator has a 'new, more judgement-led style' of prudential regulation ${ }^{64}$ (newspeak, perhaps for substantive PBR). Elsewhere, however, national governments and the EU are devising increasingly prescriptive requirements to which market participants should adhere. In the current political climate, the worse thing a regulator can be criticised of is not that it causes its financial centre to lose business, but that its regulatory approach is so favourable that it is openly celebrated as somewhere that financial institutions want to be.

\footnotetext{
${ }^{62}$ European Commission, European Financial Integration Report 2009 (Staff Working Document, SEC(2009) 1702 final, Brussels: European Commission, 2009).

${ }^{63}$ Figures taken from FSA Annual Reports 2006/2007 and 2007/2008.

${ }^{64} \mathrm{HM}$ Treasury, n 61 above, para 3.3.
} 
So what is the fate of PBR? Certainly, it has a mixed future, at least in financial regulation. Focusing first on formal PBR, here the fate of PBR depends where you look. At the UK level, as mentioned above, the Principles for Business still occupy a central role in the FSA Handbook. Moreover, wherever it is not constrained by EU legislation, the FSA has a distinct preference for framing rules in terms of broadly framed requirements supplemented by guidance. The OECD has recently produced its Principles for Efficient and Effective Financial Regulation. In Japan, as noted above, there is clear interest in PBR as an element of a move to 'better regulation'.

In the EU, however, the idea(s) of principles based regulation has never really taken hold, and if the debates on the regulation of hedge funds are any indicator, it will be a long time before it does. At the formal level, the rationale of the Lamfalussy reforms was of course to have a tiered system of rule design, with the Level 1 directives expressing the main principles, and the details being contained in the Level 2 legislative measures, and in guidance issued by the Level 3 committees. ${ }^{65}$ Whilst there are examples of individual provisions within Directives which are more 'principles' in character than others, overall the network of legislative provisions which comprises financial regulation within the EU is hard to characterise as 'principles based', at least not without so many qualifications that the label becomes almost meaningless.

At the international level, however, formal PBR is alive and well. What slows the production of principles at this level is not a preference for detailed rules but the difficulty of securing international agreement on fundamental and difficult questions. The delicate international consensus which initially developed post crisis has taken a battering in a number of areas. The fragile accord on the thorny question of whether banks should be limited in size or in their activities, for example, was broken with the unilateral announcement by the Obama administration in January 2010 that it would adopt the 'Volker rule', that no deposit-taking banks should engage in proprietary trading. ${ }^{66}$ The issue is currently being reviewed in the UK by the Independent Commission on Banking, due to report in September 2011.

However, as discussed above principles play a number of roles in regulation, particularly but not uniquely in polycentric settings. They are not simply regulatory instruments used in an attempt to affect behaviour. They can have a broader significance. As the FSAP review process illustrates, they are increasingly being used as criteria of accountability, benchmarks of performance against which national regulatory regimes are assessed. Principles are also used to establish their authors' own institutional positions within the regulatory regime. It is notable, for example, that the newly reformulated Financial Stability Board, which is being positioned and is positioning itself as the lead coordinator of global financial regulation, has issued two sets of Principles within its first eighteen months, ${ }^{67}$ more than it did in the last 10 years in its old formulation as the Financial Stability Council, in which it issued recommendations, but otherwise simply compiled a compendium of principles issued by others.

\footnotetext{
${ }^{65}$ European Commission, Final Report of the Committee of Wise Men on the Regulation of European Securities Market (Brussels: European Commission, 2001); Inter-Institutional Monitoring Group, Final Report (Brussels: European Commission, 2007). ${ }^{66}$ President B. Obama, 'Remarks by the President on Financial Reform' (White House Press Conference, 21 January 2010), at http://www.whitehouse.gov/the-press-office/remarks-president-financial-reform, now enacted in the Dodd-Frank Act 2010.

${ }^{67}$ FSB, Principles for Sound Compensation Practice (2009); FSB, Principles for Cross Border Cooperation and Crisis Management (2009).
} 
They are of course also used for a more obvious purpose as part of the drive for harmonisation of regulation across jurisdictional boundaries. However, the manner in which they are formed can be disjointed and uncoordinated. A good recent illustration of the dynamics of 'principles production' in the polycentric system of financial regulation is the development of codes on remuneration at the international, EU, and national (UK) level. In this case, despite the rhetoric of the need for greater international coordination and harmonisation, the FSA was a 'first mover', declaring that it was prepared to act unilaterally. It issued its draft code on remuneration in February 2009. This was followed (at least in time) by the communique from the G20 that principles governing remuneration should be developed. As a consequence, the Financial Stability Forum (as it still was) issued its Principles on Sound Compensation Practices on 2 April 2009, followed by Implementation Standards for the Principles in September 2009, which charged two of the international committees of regulators, IOSCO (securities) and the BCBS (banking) with the task of developing implementation proposals. Separately, regulators in Australia, Switzerland, France, and the Netherlands published principles on remuneration practices, broadly following the FSF's, and the US indicated its intention to do so.

Meanwhile, various initiatives were emanating from the EU. The Committee of European Banking Supervisors (CEBS) issued the final version of its high-level principles on remuneration on 20 April. Supervisors and firms were asked to implement them by the end of the third quarter. ${ }^{68} \mathrm{~A}$ few days later, the EU Commission published two non-binding Recommendations. The first updated its disclosure requirements for the pay of executive directors of all EU listed companies. The other addressed remuneration policies in the financial sector and recommended that Member States should ensure that financial institutions have remuneration policies for risk taking staff that are consistent with and promote sound and effective risk management. ${ }^{69}$ The Commission also published for consultation draft amendments to the Capital Requirements Directive (CRD) thatincluded provisions on remuneration, which were formalised and sent to the EU Parliament and Council in July 2009.70 None of these principles are exactly aligned with one another. The FSA code, for example, is broadly aligned to the FSB's principles, but is 'superequivalent' in a number of respects. ${ }^{71}$ Further, notwithstanding the fact that the FSA will have to implement the CRD's eventual provisions on remuneration, it decided that should act unilaterally and in advance of any EU provisions that may eventually emerge. The FSA's Code on Remuneration was finalised in October 2009 and came into force in January 2010.

The process demonstrates a number of aspects of the dynamics of norm production in polycentric regimes. First, it illustrates the persistent use of formal PBR as a regulatory tool, both in a dyadic, firm-regulator setting (eg the FSA's Remuneration Code) and a polycentric setting (FSB principles are directed at national regulators and at the other international committees of financial regulators, positioning the FSB, distributing discretion, and attempting to define 'subordinate' roles for national regulators to implement at the local level). Secondly, it demonstrates the 'multi-authorship' of principles, and the multiple roles that individual

\footnotetext{
68 CEBS, High-Level Principles for Remuneration Policies (2009).

${ }^{69}$ European Commission, Commission Recommendation on Remuneration Policies in the Financial Services Sector (C(2009) 3159$)$.

70 Proposal for a Directive of The European Parliament and of the Council amending Directives 2006/48/EC and 2006/49/EC as Regards Capital Requirements for the Trading Book and for Re-Securitisations, and the Supervisory Review of Remuneration Policies (SEC(2009) 974 final, SEC(2009) 975 final)

${ }^{71}$ For discussion, see FSA, Reforming Remuneration Practices in Financial Services (Policy Statement 09/15, London: FSA, 2009).
} 
regulators play in each of these rule-writing fora: the FSA, for example, is both contributing author of and subject to the principles emanating from the FSB, IOSCO, BCBS, and CEBS. Thirdly, it provides an example of the problems of system management and the lack of coordination that can characterise norm formation in polycentric systems, as each regulator wants to develop its own norms to suit its own local conditions and priorities. Finally, it shows that there is no hierarchy of norm formation for soft law norms: national principles do not necessarily flow from regional, and regional do not necessarily flow from the transnational. Rather the development of principles at each level can be contemporaneous; or international can follow national or regional or vice versa, and may be only loosely coordinated between the levels, if at all.

\section{SUBSTANTIVE PBR}

What of substantive or operational PBR? Here the verdict is just as mixed. The 'ideal type' constructed above consisted of five elements, not all of which need be present: modes of interpretation, enforcement, compliance focus, distribution of responsibilities within the regulatory regime, and conscious reliance on internal management, or meta-regulation. At the international level, the increased emphasis on implementation clearly opens the possibility for substantive PBR to be adopted, but proper evaluation of that system has to be left for another time. Focusing again on the dyadic context of substantive PBR, the regulator-regulatee relationship, and on the UK, then the interpretive approach has not changed: interpretation of both rules and principles within the FSA Handbook is still characterised by purposive interpretation and consequentialist reasoning, in fact perhaps even more than it was pre-crisis. The FSA's enforcement activities have certainly intensified, but the trend for taking actions for breaches of Principles alone continues. The main shift here has been with respect to the target of enforcement actions, with senior individuals of large institutions now being targeted when they were not before, and fine levels being raised.

Central to PBR is a reliance on firms' internal management (or in polycentric PBR, on the governance infrastructure of national states or other actors in the regime). Here the FSA has had an interesting journey, and one that is instructive for proponents of meta-regulation or management based regulation. One of the statutory principles of 'good regulation' that the FSA is required to observe requires it to have regard to 'the responsibilities of those who manage the affairs of authorised persons'. ${ }^{2}$ As the FSA explained early on in its life, ' $[\mathrm{t}$ his principle is designed to guard against unnecessary intrusion by the regulator into firms' business and requires us to hold senior management responsible for risk management and controls within firms. ${ }^{73}$ The provision was used increasingly by the FSA to defend the deferential approach that it has taken to senior management, and in particular for not intervening in firms' business decisions. ${ }^{74}$ As noted above, focus on monitoring the existence of systems and processes has now been replaced with a far more intensive focus on ensuring that those systems and processes are delivering the

\footnotetext{
72 Financial Services and Markets Act s 2(3)(b).

${ }^{73}$ FSA, A New Regulator for a New Millennium (London: FSA, 2000).

${ }^{74}$ See eg Turner Review, n 15 above.
} 
right outcomes. Far from trusting senior management, the attitude is now that such an important aspect of PBR is not possible: to reiterate Hector Sants' memorable phrase, principles based regulation is not possible for people who have no principles. So to the extent that PBR meant a focus on outcomes, then that is retained and indeed enhanced. However, a central element of PBR is trust, and that trust has gone. Its disappearance has cast substantive PBR a potentially fatal blow.

\section{PBR AND RISK BASED REGULATION}

Finally, as an aside, it is worth considering the relationship between PBR and risk based regulation (RBR), at least within the FSA. The FSA has maintained that it is an evidence based, risk based, principles based, and now outcomes focused regulator, all at the same time. By evidence based, it means it will only regulate where there is an identifiable market failure, and the costs of intervention are less than the benefits to be gained from intervening. It does not always have the room to do this given the extent to which policy and legislation emanate from the EU, but it has nonetheless conducted cost-benefit analyses routinely since its inception, as indeed it is required to do under its statutory duties. By risk based, it means that it will focus its supervisory resources on matters that pose the greatest risk to its statutory objectives..$^{75}$ It has never been particularly clear how its risk-based models of supervision tie in with principles based regulation. The risk indicators do not interact with the principles; in fact they do not particularly interact with the Handbook at all. This can partly be explained by historical development: the FSA's risk based regime is built around risks to its four statutory objectives. It was being formulated more or less at the same time as the Principles for Business, but in a separate part of the organisation and led by individuals who came out of different parts of the pre-FSA institutional structure: one from the old Securities and Investments Board, the other from the Bank of England. ${ }^{76}$

But timing is not the only reason for the dissonance. There is potentially an operational mismatch between PBR and RBR that arises from the logic of RBR itself. One of the key points of risk based regulation is that regulators often have more rules to ensure compliance with than they have resources available. Consequently, one of the first messages of RBR is that regulators should start with 'risks not rules'. This framing of supervision in terms of 'risks not rules' is to help regulators move away from a 'tick box' attitude to compliance, when it checks compliance with every rule, to a more outcomes based and risk based approach to supervision. ${ }^{77}$ The rules themselves, including any principles, play a rather ambivalent role in risk-based regulation. Their point of entry into the supervisory process is not in the design of the risk based system, or even its implementation. Rather it comes later, when a regulator is considering taking enforcement action against conduct or activities which it considers to be posing too high a risk. The danger of course then is that there will be found to be a mismatch between the rules and the risks: that the rules do not focus on the risks and thus there is a critical lacuna in the regulatory regime.

\footnotetext{
${ }^{75}$ Both of these were set out early in its life: ibid.

${ }^{76} \mathrm{~J}$. Black, 'The Emergence of Risk Based Regulation and the New Public Management in the UK' (2005) Public Law 512.

${ }^{77}$ For discussion, see J. Black, 'Risk Based Regulation: Choices, Practices and Lessons Being Learned' (paper prepared for the OECD, December 2008) in OECD, Risk and Regulatory Reform (OECD, Paris, 2010).
} 
In principle, $\mathrm{PBR}$ should complement RBR, for one of the advantages of principles is that they can usually be called upon to fill the gap between risks and detailed rules. However, in the FSA's case, Principles are not used to frame the 'risk to objectives' that is assessed in the riskbased supervisory framework. Rather they are brought in at the enforcement stage, once it has been decided that a risk has crystallised. This difference is partly due to the contrasting natures of the regulatory interventions: enforcement is an ex post process which looks backwards; risk based supervision is ex ante, and is meant to look forwards. However, there is no analytical reason why the Principles could not be used more clearly to set the supervisory agenda. That they do not suggests the persistence of the 'twin track' operation of PBR and RBR in the FSA's supervisory process.

\section{CONCLUSIONS}

Although this discussion has focused on PBR, in orientating its discussion around the ideal types' proposed at the outset it risks taking regulators' rhetoric too seriously. In practice, characterising a regulatory regime as rules based or principles based does not take us very far, descriptively or normatively. It is hard to classify any one regulatory regime as being either entirely rule based or entirely principles based; the better question is what is, and should be, the relative roles of each. Neither principles nor rules usually function particularly successfully without the other. ${ }^{78}$ However debates on PBR are in fact rarely about the linguistic structure of written norms. They are usually much more about the nature of regulatory practices, of regulatory relationships, and as to who should have the final say in interpreting the rule or principle. Moreover, it is the substantive nature of these relationships and practices which are far more relevant for understanding the operation of a regulatory regime than what the rulebooks look like. Furthermore, the rhetoric needs to be separated from the reality, and not necessarily believed. PBR can be used as a marketing label - used to conjure up a regulatory Utopia - as it was by politicians in the pre-crisis battle for market share. Conversely, it can be a derogatory label used to conjure up regulatory ineffectiveness - as it is post-crisis to explain what went wrong.

However, as a (constructed set) of substantive strategies of regulation, in practice PBR is complex and often paradoxical. ${ }^{79}$ As for its future: for the moment, its fate is bound up with the association that PBR is light touch regulation. As has been illustrated above, PBR need not equate to 'light touch' regulation, but that more complex and tempering message is not one which politicians set on increasing their control over banks, and over regulators, currently want to hear. PBR, both formal and substantive, and in both dyadic and polycentric relationships, is predicated, however, on extensive trust between the actors in the regulatory regime. Wherever that trust is lacking there is little scope for PBR to operate in any substantive way, and little chance that others will be afforded much discretion through the use of principles in the

${ }^{78}$ See eg J. Braithwaite, 'A Theory of Legal Certainty' (2002) 27 Australian Journal of Legal Philosophy 47.

79 J. Black, 'The Forms and Paradoxes of Principles Based Regulation' (2008) Capital Markets LJ 425. 
rulebooks. As for which strategy or set of regulatory strategies is the more effective: the financial crisis was a global experiment in the effectiveness of a wide range of regulatory techniques and institutional structures of financial regulation. All of them failed at least once. Governance and regulatory scholars and 'better regulation' practitioners rarely hold out much hope for the effectiveness of 'command and control' or detailed rules based regulation, so failures of those techniques will come as no surprise. In contrast it is the failure of many of the 'new governance' techniques of regulation which should prompt the greatest thought. 